\title{
Special issue: Infrastructure mega-project management on the Hong Kong-Zhuhai-Macao Bridge project
}

C The Author(s) 2018. Published by Higher Education Press. This is an open access article under the CC BY license (http:// creativecommons.org/licenses/by/4.0)

Infrastructure mega-projects (IMPs) are large-scale engineering deliverables, such as hydropower projects, highspeed railways, expressway networks, gas pipeline projects, and long-span bridges. IMPs provide fundamental public services for social production, economic development, and daily life, and form the backbone of modern societies. The importance of IMPs has necessitated an improved understanding of how these facilities are managed.

Theoretically, IMPs are complex artificial systems with integrity comprising the basic foundation of their management activities and processes. In addition, the complexity of IMP management cannot be addressed through reductionism and the principle of superposition with regard to integrity. Complex integrity should be considered because this concept represents the non-superposition of integrity in complex systems and illustrates the underlying causes and connotations of the complexity of IMPs. Accordingly, the management of IMPs should be deeply rooted in the thinking and methodology stemmed from complex integrity to solve practical problems.

Moreover, complexity is the nature of IMP management. Thus, the key to analyzing and solving management problems is to deal with and control complexity. When we abstract and correlatively systemize the attributes of a physical system to form the logic system of the innate complexity of IMPs (i.e., project virtuality), project virtuality should be utilized to assist and support the subject to simplify the recognition and analysis of management complexity through assumption and ideal degradation behaviors. Thereafter, the physical complexity of IMPs could be restored following the logic of the project entity, thereby guaranteeing the integrity and authenticity of IMPs.

In practice, the Hong Kong-Zhuhai-Macao Bridge (HZMB) project offers immense opportunity for the application of complex integrity to the management practices of IMPs. The meta-synthesis based on integrity and complexity breeds management thinking, methodology, and method system of complex integrity, that is, the complex integrity management system of the HZMB project. This system not only plays a critical role in the construction of the HZMB project, but also greatly advances the theoretical principles and methodology of the IMP management.

This special issue is based on the success of the HZMB project and comprises a collection of research papers contributed by a group of leading experts who are dedicated to providing state-of-the-art development in the academic and practical fields of the IMP management. These papers cover hot topics in the IMP management, including fundamental theories, organizational models under the context of government-market ambidexterity, decision-making mechanisms, design-build (DB) modes, on-site management, social responsibility, environmental protection, and financing risks. These studies demonstrate the numerous applications of complex integrity in the practical management of the HZMB project, as well as introduce a series of innovative and novel theories, methods, and tools. Moreover, these studies reflect the novel academic opinions of Chinese scholars and the contributions of eastern philosophy and cultural logic to IMP management.

To address innovative technology and deep uncertainty during the design and construction process of IMPs, Mai et al. developed a meta-synthesis management framework for complex projects from the perspective of the science of complexity. This framework provides a novel method to integrate the two strategies of exploration and exploitation into the mega-project management. In particular, the exploration strategy could transform complex problems into systematic problems, which the exploitation strategy could solve thereafter. The qualitative analysis of the bridge deck pavement project further shows that in the design phase of IMPs, innovative integration is used to explore new engineering technology and knowledge. By contrast, functional integration is used to define the system architecture, interface relationship, technical index, and other functions. In the construction phase, adaptive integration benefits 
the construction of an engineering organization system. Hence, efficient integration could improve the construction performance.

Zhao et al. proposed the novel concept of the IMP complex ecosystem, which develops a profound understanding of IMPs from a broader perspective that organic links exist among engineering, society, economy, and ecology. A logistical model is introduced by considering engineering integrity and analyzing the exchange of materials, energy, and information among the subsystems of engineering, society, economy, and ecology to determine the structures, functions, evolutionary patterns, and coupling mechanisms. A case study of Sousa chinensis is conducted to test the applications of the theoretical model in ecological protection.

The HZMB project is deeply embedded in the context of "One country, Two systems" and lacks the common legal environment and legal authorities during the design and construction periods. To degrade the institutional complexity of the cross-border IMP, Zhu et al. systematically analyzed the complexity of the decision-making process related to the HZMB project and provided the general principles involved in the decision-making management and design. They also explicitly described the structure of the decision-making management system, adaptive behaviors, and specific coordination mechanisms of the different targets in different stages.

Zhang et al. used the analysis of the complex integrity of the island-tunnel subproject of the HZMB project as basis to propose an improved DB mode, in which the owner provides a preliminary design and has the right to form and manage the union body. This new mode provides an efficient method to understand the main contradictions and integrate the effective resources because this approach degrades the complex integrity in multiple dimensions and at multiple levels, thereby effectively addressing the complexity management of IMPs.

From the institutional perspective, Hu et al. analyzed the design and operation of a multi-level governance system for delivering IMPs with institutional complexity caused by market transitions. The three dimensions of the governance system (i.e., structure, elements, and dynamics) are scrutinized through an integrative three-level framework based on the inductive case study of the HZMB project. The results revealed that the co-evolution between governments and markets in China has shaped the vertical levels of the megaproject governance system and has further affected the evolution and operation of these institutions across various stages of project development.

Chan et al. developed a fuzzy evaluation model for assessing the suitability of procuring construction megaprojects by considering the risk exposure of these projects. The main body of the HZMB project is used to demonstrate how the model could be used in real-life situations. In particular, four critical risk groups are employed to evaluate the overall risk: construction and land, commercial, operational, and political risks. The case project is determined to be unsuitable for the Public-Private Partnership (PPP) approach, thereby supporting the decisions made by the host government and by previous studies.

Zhou et al. proposed a new management mode for the construction site, which is called smart construction site, to achieve safe, efficient, and high-quality construction. The three key elements of the smart construction site are information support platform, collaborative work, and intelligent construction management. The case study on the immersed tunnels of the HZMB project demonstrates that the smart construction site is beneficial for determining the interconnection of the construction information, collaborative works of equipment, systems, and participants. Future research on the smart construction site is proposed to reinforce the collaborative work among the participants in the entire construction processes and provide information support for the operation and maintenance of the facility once the project commences operations.

Regarding the supplier development of the HZMB project, Zeng et al. employed a comparative case study to show the obvious differences between the construction and manufacturing industries in terms of development motives, supplier selection, quality management, production modes, owner participation, and risks. The critical influence factors include incentives, collaboration, future market, trust, and bilateral communication. Thereafter, decisionmaking framework models are proposed to design incentive mechanisms by focusing on the incentives for the improvement of product quality and production capability.

From the perspective of social responsibility, Liu et al. focused on the environmental protection and biodiversity in the construction of IMPs. These researchers provided a panoramic view of the impact of the HZMB project on Sousa chinensis and developed an ecological compensation mechanism for IMPs, including concrete measures, decisionmaking processes, and organizational collaboration. The successful experience enriches the understanding of the ecological compensation practice throughout the lifecycle of IMPs.

Chen et al. drew on the knowledge-based view and innovation network theory and identified the heterogeneous characteristics of the IMP innovation. Four dimensions, (i.e., diversity of innovation entities, dynamic nature of the IMP stages, unique nature of IMPs, and temporary nature of IMP teams) are considered when addressing the complexity of the IMP innovation. Thereafter, a framework is proposed to analyze the formation mechanism of the IMP innovation island from three dimensions, namely, horizontal, vertical, and longitudinal innovation islands. 
This special issue presents an important step in the development of theories and methodologies for infrastructure mega-project management. The guest editors are delighted to compile these papers and we believe that these studies will provide illuminating insights into the complexity and diversity of the IMP management research. We are extremely grateful to all the authors who have made substantial contributions to this special issue. We also express our gratitude to all the reviewers who took special care and attention in improving all the papers to comply with the high publication standards of Frontiers of Engineering Management.

\author{
Guest Editors-in-Chief \\ Chongqing GUO \\ Professor, Tongji University, China \\ E-mail: guocq@mail.tongji.edu.cn \\ Zhaohan SHENG \\ Professor, Nanjing University, China \\ E-mail: zhsheng@nju.edu.cn
}

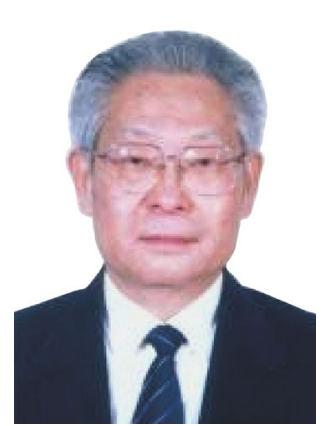

Prof. Chongqing Guo is a Professor of School of Economics and Management, Tongji University; Academician of Chinese Academy of Engineering. He was the Director of Management Sciences Department of the National Natural Science Foundation of China and an Associate Director of the Engineering Management Department of the Chinese Academy of Engineering.

Devoting himself to engineering design, consulting, and industrial development strategy planning, Prof. Guo has made outstanding contributions to scientific and technological progress in Chinese industrialization development. He served as the chief designer of more than 30 national and ministry-level major construction projects, including China's first industrial project (Shanghai Machine Tool Project, funded by the World Bank) and the first independent consulting project undertaken by Chinese engineering consultants (The feasibility study on Shenyang Industrial Reform Project, funded by the World Bank). He has won one State Science and Technology Award, five Ministry-level Science and Technology Awards, one gold-medal and three silver medals of National Excellent Designs, three First Prizes of Excellent Design of China's Ministry of Machinery, and he was honored with the title of National Engineering Design Master.

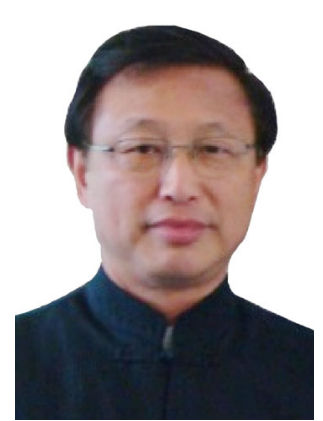

Prof. Zhaohan Sheng is a Professor of School of Management and Engineering, Nanjing University. $\mathrm{He}$ is the Director of Jiangsu Logistics Technology and Engineering Center, Director of Jiangsu System Science Institute, Director of Complex Engineering Management Institute of Nanjing University, Dean of School of Complex Engineering Management in Tongji University, and Director of Nationwide Logistics Engineering Cooperative Group on Master of Engineering.

Focusing on the research of system science and social science computing experiment, Prof. Sheng has made outstanding achievements in megaproject management, supply chain management, and socio-economic-environment compound system management. He presided over the major and key projects of National Natural Science Foundation, the major project of National Social Science Fund, the National Key Technology R\&D Program of the Ministry of Science and Technology, the State's major projects and large enterprise consulting and research projects. He has won the Second Class Prize of The State Scientific and Technological Progress Award, Outstanding Class Prize of National Ministry of Machine-Building Industry Scientific and Technological Progress Award, First Class Prize in National Ministry of Education Scientific and Technological Progress Award, First Class Prize in Jiangsu Scientific and Technological Progress Award, First Class Prize in Chinese University Scientific and Technological Progress Award, and First Class Prize in Jiangsu Philosophy of the Social Science. 